BMJ Open

Diabetes

Research

\& Care

\section{Serum calcification propensity is associated with HbA1c in type 2 diabetes mellitus}

To cite: Mencke $\mathrm{R}$, van der Vaart $A$, Pasch $A$, et al. Serum calcification propensity is associated with $\mathrm{HbA} 1 \mathrm{C}$ in type 2 diabetes mellitus. BMJ Open Diab Res Care 2021;9:e002016. doi:10.1136/ bmjdrc-2020-002016

Received 18 November 2020 Revised 4 January 2021 Accepted 18 January 2021

\section{Check for updates}

(c) Author(s) (or their employer(s)) 2021. Re-use permitted under CC BY. Published by BMJ.

${ }^{1}$ Department of Pathology and Medical Biology - Division of Pathology, University of Groningen, University Medical Center Groningen, Groningen, The Netherlands

${ }^{2}$ Calciscon AG, Nidau,

Switzerland

${ }^{3}$ Department of Internal

Medicine, Isala, Zwolle, The

Netherlands

${ }^{4}$ Department of Internal Medicine, University of Groningen, University Medical Center Groningen, Groningen, The Netherlands

${ }^{5}$ Diabetes Centre, Isala, Zwolle, The Netherlands

Correspondence to Dr Peter R van Dijk; p.r.van.dijk@umcg.nl

\section{ABSTRACT}

Introduction Serum calcification propensity is emerging as an independent predictor for cardiovascular outcomes in high-risk populations. Calcification propensity can be monitored by the maturation time of calciprotein particles in serum ( $T_{50}$ test). $A$ low $T_{50}$ value is an independent determinant of cardiovascular morbidity and mortality in various populations. Aim was to investigate the $T_{50}$ and its relationship to type 2 diabetes mellitus.

Research design and methods Using nephelometry, serum $\mathrm{T}_{50}$ was cross-sectionally measured in 932 stable patients with type 2 diabetes mellitus ( $55 \%$ male) with a median age of 66 (62-75) years, diabetes duration of $6.5(3.0-10.2)$ years and hemoglobin A1c ( $\mathrm{HbA1c}$ ) of 49 (44-54) $\mathrm{mmol} / \mathrm{mol}$.

Results Serum $T_{50}$ was normally distributed with a mean value of $261 \pm 66 \mathrm{~min}$. In linear regression, serum $\mathrm{T}_{50}$ was lower in women and current smokers. A lower $\mathrm{T}_{50}$ value was found in patients with a higher HbA1c or higher systolic blood pressure, insulin users and patients with a longer history of diabetes. The association with $\mathrm{HbA1C}$ was independent of other determinants in multivariable analysis. There was no association between $\mathrm{T}_{50}$ and previous macrovascular events or the presence of microvascular disease.

Conclusions Serum calcification propensity is independently associated with glycemic control, suggesting that a lower $\mathrm{HbA1c}$ may be associated with better cardiovascular outcomes. Retrospective analysis could not establish an association between a history of macrovascular events and $\mathrm{T}_{50}$, and prospective studies will have to be performed to address this hypothesis.

Trial registration number NCT01570140.

\section{OBJECTIVE}

Despite intensive glycemic control and adequate management of cardiovascular risk factors, type 2 diabetes mellitus (T2DM) is accompanied by microvascular disease, including retinopathy, nephropathy and neuropathy, and macrovascular disease. Individuals with T2DM are prone to developing vascular calcifications, which considered playing a causal role in the etiology of diabetic complications. ${ }^{1}$

\section{Significance of this study}

What is already known about this subject?

- Diabetes mellitus (DM) is accompanied by increased vascular calcifications and an excess cardiovascular morbidity.

- The $\mathrm{T}_{50}$ score is a novel functional blood test that quantifies serum calcification propensity.

What are the new findings?

- This is the first study to determine associations of $\mathrm{T}_{50}$ with parameters of type $2 \mathrm{DM}$.

- In this large cohort of primary care treated persons with type $2 \mathrm{DM}$, hemoglobin A1c was significantly associated with $\mathrm{T}_{50}$, suggesting that that better glycemic control may correlate with a less pronounced development of vascular calcification.

How might these results change the focus of research or clinical practice?

- Although promising, it has to be determined if the $T_{50}$ value has predictive value for cardiovascular disease in the type $2 \mathrm{DM}$ population.

Previously, vascular calcifications were considered a result from passive precipitation of calcium and phosphate. Nowadays, the process of calcification is considered a consequence of a disequilibrium of a between calcification stimulating and inhibiting factors. ${ }^{2}$ Evidence exists that in persons with diabetes this equilibrium is unbalanced, leading to ectopic calcification in the media of the vessel wall, atherosclerotic plaque progression and subsequent cardiovascular events. ${ }^{1-6}$ The process of calcification is thought to be (at least partially) mediated by calciprotein particles $(\mathrm{CPPs})^{7-9}$ that naturally circulate in the blood. Primary CPPs contain amorphous calcium phosphate, whereas secondary CPPs contain crystalline calcium phosphate. ${ }^{10-13}$ Secondary CPPs have the capability of inducing calcification of, for example, vascular smooth muscle cells, ${ }^{7}$ so the rate of 
primary-to-secondary CPP transitioning is viewed to be a measure of the serum anticalcification buffer capacity.

This increased formation and maturation and defective clearance of CPP may be an important novel cardiovascular risk factor (so-called mineral-stress hypothesis). ${ }^{14}$ Indeed, amorphous CPP1 exerted minor cellular responses in macrophage cell lines, while CPP2 appeared to induce oxidative stress and inflammation in macrophages, ${ }^{15}$ and oxidative stress, inflammation, and calcification in primary human aortic smooth muscle cell cultures. ${ }^{16}{ }^{17}$ The $T_{50}$ serum calcification propensity test has been developed to allow for quantification of the serum anticalcification buffer capacity. ${ }^{18}$ This novel $\mathrm{T}_{50}$ test measures in vitro how rapidly CPP2 are formed in a patient blood sample. In other words, the result of the $T_{50}$ test reflects the velocity of calcium phosphate crystallization in blood with lower $T_{50}$ values indicating increased calcification propensity. Results of the $\mathrm{T}_{50}$ test have been determined to be an independent mortality predictor in both chronic kidney disease (CKD) ${ }^{19}$ and in renal transplantation patient populations. ${ }^{20} 21$

Because any serum test that can be used reliably to assess vascular calcification would be considered an asset in assessing cardiovascular risk in patients, we aimed to assess the association of the $\mathrm{T}_{50}$ test with parameters of T2DM management in a large cohort of stable patients.

\section{RESEARCH DESIGN AND METHODS}

\section{Study design and aims}

This is a cross-sectional study. Baseline data and blood samples were obtained from the e-VitaDM study and Zwolle Outpatient Diabetes project Integrating Available Care (ZODIAC) study. The e-VitaDM study was designed to assess the feasibility of using an online platform in routine primary healthcare for subjects with T2DM. This study was conducted in general practices that are connected to the Care Group Drenthe in the Drenthe region of the Netherlands (www.hzd.nu). Fifty-two out of the 110 general practices of the Care Group Drenthe agreed to participate; in these practices, approximately 8300 patients with T2DM were treated.

As a prespecified part of the e-VitaDM study, patients were assessed in a long-term follow-up. This prospective arm was nested within the ZODIAC study. Both the e-VitaDM and the ZODIAC study are described in detail elsewhere. ${ }^{22}$ The protocol was also registered on clinicaltrials.gov. All patients gave informed consent.

The primary aim of the present study was to investigate the cross-sectional association between $\mathrm{T}_{50}$ and indices of T2DM management, in particular hemoglobin A1c (HbAlc).

\section{Patients}

Patients were recruited during a regular check-up by their (diabetes) practice nurse. Patients were included from May 2012 to September 2014. Patients with T2DM, aged $\geq 18$ years and the general practitioner as main care provider for T2DM were eligible for participation. For the e-VitaDM study, there were no exclusion criteria. A total of 1710 out of 3988 patients, who were asked to participate in the eVita-DM study, gave written informed consent. Of these patients, 730 had no blood samples or were not included in the ZODIAC study and in 48 there was insufficient blood available to measure $\mathrm{T}_{50}$. Consequently, the final study sample consisted of 932 patients.

\section{Measurements}

Baseline demographic data included sex, age, duration of diabetes, BMI, alcohol use and smoking habits. Information concerning alcohol use and smoking habits was derived from questionnaires at baseline. Additional medical data were extracted from the diabetes-specific database at the Isala Diabetes Centre. This centre gathers data of primary care treated patients with T2DM in a large part of the Netherlands on a yearly basis to provide benchmark information to general practitioners. This database includes data on physical examination, use of medication, and laboratory blood and urine tests. The following data were extracted: date of diabetes diagnosis, height, weight, diastolic and systolic blood pressure, cholesterol, HbA1c, serum creatinine, urine creatinine, urine albumin, urine creatinine:albumin ratio, the presence of macrovascular complications and microvascular complications.

Macrovascular complications included (a history of) angina pectoris, myocardial infarction, percutaneous transluminal coronary angioplasty, coronary artery bypass grafting, cerebrovascular accident or transient ischemic attack. Microvascular complications included diabetic retinopathy, albuminuria and diabetic peripheral neuropathy. Microalbuminuria was defined as an albumin:creatinine ratio between $2.5-25 \mathrm{mg} / \mathrm{mmol}$ in men and $3.5-35 \mathrm{mg} / \mathrm{mmol}$ in women. Macroalbuminuria was defined as a ratio higher than $25 \mathrm{mg} / \mathrm{mmol}$ and $35 \mathrm{mg} / \mathrm{mmol}$ for men and women, respectively. ${ }^{23} \mathrm{An}$ ophthalmologist determined presence of diabetic retinopathy biannually. Foot sensibility was tested with 5.07 Semmes-Weinstein monofilaments. Diabetic polyneuropathy was defined as two or more errors in a test of three, at least affecting one foot. Blood glucose lowering therapy was categorized into: dietary measures only, oral blood glucose lowering drugs including metformin, sulfonylurea derivatives, thiazolidinediones and dipeptidyl peptidase- 4 inhibitors, and insulin therapy.

At baseline, aliquots of blood samples were stored at $-80^{\circ} \mathrm{C}$ (without thawing) until measurement. Serum $\mathrm{T}_{50}$ was measured as described previously. ${ }^{6}$ Briefly, thawing was performed at $4^{\circ} \mathrm{C}$ for 48 hours, before vortexing and centrifugation. Then, samples were pipetted in triplicate in 384-well plates at $37^{\circ} \mathrm{C}$. Supersaturated stock solutions of calcium $(35 \mu \mathrm{L})$ and phosphate $(25 \mu \mathrm{L})$, both $\mathrm{pH} 7.40$ at $37^{\circ} \mathrm{C}$, were mixed with $40 \mu \mathrm{L}$ serum, and nephelometry was performed for $600 \mathrm{~min}$ in a Nephelostar nephelometer (BMG Labtech, Germany). Non-linear regression 
analysis was performed on the curves to determine the half-maximal precipitation time.

\section{Statistical analysis}

Normally distributed data are presented as mean $\pm \mathrm{SD}$, and non-normally distributed data are presented as median (IQR). Means or medians were compared between groups using Student's t-test or analysis of variance, or the Mann-Whitney U test or Kruskal-Wallis test, as appropriate. Categorical variables were compared using the $\chi^{2}$ test or Fisher's exact test. Normality of variables was assessed using frequency distribution histograms and $Q Q$ plots. Univariable linear regression analysis was used to investigate associations between variables that showed a normal distribution of the residuals. Multivariable linear regression analysis was used to investigate associations between a dependent variable and multiple independent covariates, for which a backward regression model was established. Regression models were checked for linearity, homoscedasticity, absence of multicollinearity, independence and normality of errors. A p value $<0.05$ was considered statistically significant. Univariable logistic regression analysis was used to assess the relationship

Table 1 Baseline characteristics stratified by tertile according to $T_{5}$

\begin{tabular}{|c|c|c|c|c|}
\hline & $\begin{array}{l}\text { Overall } \\
(\mathrm{N}=932)\end{array}$ & $\begin{array}{l}\text { Tertile 1 } \\
\text { (<235 min) } \\
\text { (N=311) }\end{array}$ & $\begin{array}{l}\text { Tertile } 2 \\
(235-293 \mathrm{~min}) \\
(\mathrm{N}=310)\end{array}$ & $\begin{array}{l}\text { Tertile } 3 \\
\text { (>293 min) } \\
\text { (N=311) }\end{array}$ \\
\hline Age (years) & $65.8(58.5-72.0)$ & $65.7(57.9-71.7)$ & $65.7(59.7-72.3)$ & $65.9(58.7-71.7)$ \\
\hline Sex, \% male $(\mathrm{n})$ & $54.7(510)$ & 44.7 (139) & $53.9(167)$ & $65.6(204)$ \\
\hline Smoking, \% current (n) & $17.0(157)$ & $23.7(73)$ & $15.2(47)$ & $12.0(37)$ \\
\hline Alcohol use, \% (n) & $36.1(273)$ & $30.1(78)$ & $38.2(91)$ & $40.2(104)$ \\
\hline BMI $\left(\mathrm{kg} / \mathrm{m}^{2}\right)$ & $29.3(26.7-33.0)$ & $29.7(27.1-33.4)$ & $29.1(26.4-32.8)$ & $29.1(26.7-32.7)$ \\
\hline $\mathrm{SBP}(\mathrm{mm} \mathrm{Hg})$ & $135(125-144)$ & $136(124-145)$ & $135(125-144)$ & $134(125-141)$ \\
\hline $\mathrm{DBP}(\mathrm{mm} \mathrm{Hg})$ & $80(70-83)$ & $80(72-84)$ & $76(70-82)$ & $80(72-82)$ \\
\hline Duration of diabetes (years) & $6.5(3.0-10.2)$ & $6.7(3.2-10.5)$ & $7.2(2.9-10.5)$ & $5.9(2.79 .7)$ \\
\hline $\mathrm{HbA} 1 \mathrm{c}(\mathrm{mmol} / \mathrm{mol})$ & $49(44-54)$ & $50(45-55)$ & $49(43-54)$ & $48(44-53)$ \\
\hline Total cholesterol (mmol/L) & $4.3(3.7-4.9)$ & $4.2(3.7-4.9)$ & $4.3(3.7-4.9)$ & $4.3(3.7-4.8)$ \\
\hline HDL cholesterol (mmol/L) & $1.2(1.0-1.5)$ & $1.3(1.0-1.5)$ & $1.2(1.1-1.5)$ & $1.2(1.0-1.4)$ \\
\hline Total cholesterol/HDL ratio & $3.4(2.8-4.2)$ & $3.3(2.7-4.3)$ & $3.4(2.8-4.1)$ & $3.5(2.9-4.3)$ \\
\hline LDL cholesterol (mmol/L) & $2.3(1.8-2.8)$ & $2.2(1.7-2.8)$ & $2.4(1.8-2.8)$ & $2.3(1.9-2.9)$ \\
\hline Triglycerides (mmol/L) & $1.5(1.1-2.0)$ & $1.5(1.1-2.1)$ & $1.4(1.0-2.0)$ & $1.5(1.0-2.1)$ \\
\hline History of macrovascular event, \% (n) & $25.1(234)$ & $25.4(79)$ & $23.5(73)$ & $26.4(82)$ \\
\hline History of AP, \% (n) & $7.4(59)$ & $5.8(18)$ & $7.1(22)$ & $9.3(29)$ \\
\hline History of MI, \% (n) & $8.6(80)$ & $9.6(30)$ & $5.8(18)$ & $10.3(32)$ \\
\hline History of PCI, \% (n) & $2.6(24)$ & $3.5(11)$ & $2.3(7)$ & $1.9(6)$ \\
\hline History of CABG, \% (n) & $4.9(46)$ & $5.5(17)$ & $4.8(15)$ & $4.5(14)$ \\
\hline History of TIA, \% (n) & $3.3(31)$ & $1.6(5)$ & $4.5(14)$ & $3.9(12)$ \\
\hline History of stroke, $\%(n)$ & $6.1(57)$ & $5.5(17)$ & $7.4(23)$ & $5.5(17)$ \\
\hline History of microvascular event, \% (n) & $35.2(293)$ & $35.4(97)$ & $35.3(97)$ & $34.9(99)$ \\
\hline History of retinopathy, \% (n) & $4.6(38)$ & $7.3(20)$ & $2.2(6)$ & $4.3(12)$ \\
\hline History of peripheral neuropathy, $\%$ (n) & $19.7(171)$ & $18.5(53)$ & $20.7(60)$ & $19.7(58)$ \\
\hline History of albuminuria, $\%(n)$ & $13.7(128)$ & $13.8(43)$ & $13.5(42)$ & $13.8(43)$ \\
\hline eGFR, $\mathrm{mL} / \mathrm{min} / 1.73 \mathrm{~m}^{2}$ & $74(61-86)$ & $73(60-89)$ & $73(61-85)$ & $75(63-87)$ \\
\hline Albumin/creatinin ratio & $0.8(0.4-1.5)$ & $0.7(0.4-1.5)$ & $0.8(0.4-1.5)$ & $1.0(0.4-1.5)$ \\
\hline Diet, \% (n) & $19.4(181)$ & $17.2(53)$ & $19.0(59)$ & $22.2(69)$ \\
\hline Oral glucose lowering drugs, \% (n) & $78.1(728)$ & $79.4(247)$ & $79.0(245)$ & 75.9 (236) \\
\hline Insulin therapy, \% (n) & $13.0(121)$ & $16.4(51)$ & $12.3(38)$ & $10.3(32)$ \\
\hline Cholesterol-lowering drugs, \% (n) & $79.6(741)$ & $77.2(240)$ & $82.3(255)$ & $79.4(246)$ \\
\hline Antihypertensive therapy, \% (n) & $84.7(788)$ & $84.8(263)$ & $85.2(264)$ & $84.2(261)$ \\
\hline
\end{tabular}

Data are presented as percentage (number), mean (SD) or median (IQR).

$\mathrm{AP}$, angina pectoris; BMI, body mass index; CABG, coronary artery bypass grafting; DBP, diastolic blood pressure; eGFR, estimated glomerular filtration rate; HbA1c, hemoglobin A1c; HDL, high-density lipoprotein; LDL, low-density lipoprotein; MI, myocardial infarction; $\mathrm{PCl}$, percutaneous coronary intervention; SBP, systolic blood pressure; TIA, transient ischemic attack. 


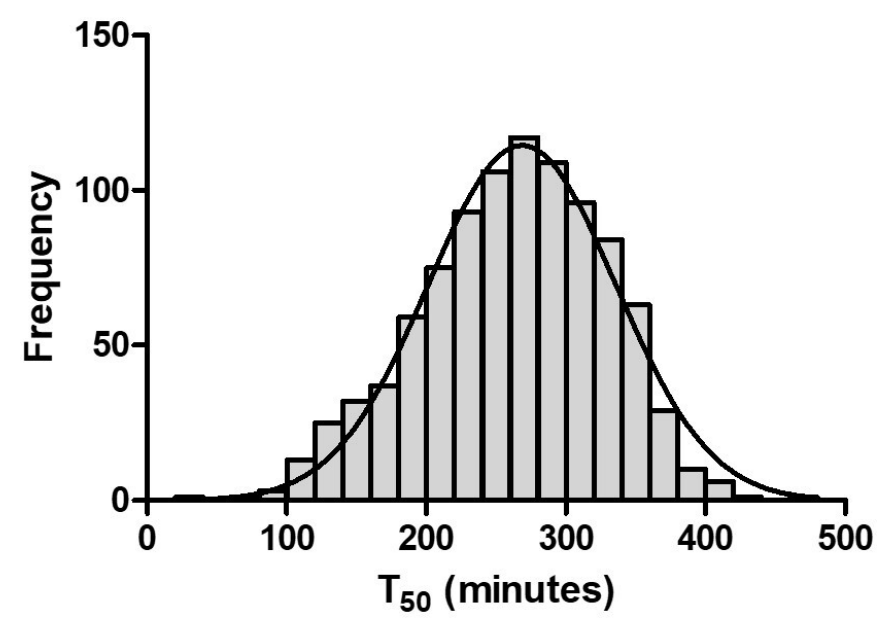

Figure 1 Frequency distribution of serum $\mathrm{T}_{50}$. The serum $\mathrm{T}_{50}$ values (in minutes) approximate a normal distribution (indicated by the Gaussian curve).

between a binary outcome dependent variable and an independent covariable. All statistical analyses were performed using SPSS V.24 (IBM, USA).

\section{RESULTS}

Patient baseline characteristics are shown in table 1, both overall and, for descriptive purposes, stratified by $T_{50}$ tertile with the middle tertile ranging from 235 to $293 \mathrm{~min}$. In brief, the population had a median age of 65.8 years (62-75), $54.7 \%$ was male, mean diabetes duration was 6.5 (3.0-10.2) years, baseline HbAlc was 49 (44-54) mmol/ mol and median (estimated) renal function in this study was $74(61-86) \mathrm{mL} / \mathrm{min} / 1.73 \mathrm{~m}^{2}$. A total of 234 patients (25.1\%) had a history of a macrovascular event. A total of 205 patients $(30.8 \%)$ had a documented microvascular complication. Treatment of diabetes consisted strictly of dietary interventions for $19.5 \%$ of patients, whereas $67.5 \%$ took oral blood glucose lowering drugs and $13.0 \%$ used insulin therapy.

The distribution of serum $T_{50}$ is depicted in figure 1 , with a mean value of $261 \pm 66 \mathrm{~min}$. While age was not significantly different across tertiles $(\mathrm{p}=0.664)$, women had significantly lower $\mathrm{T}_{50}$ values $(\mathrm{p}<0.001)$. Similarly, a lower $T_{50}$ value was associated with the status of current smoker, while a higher $\mathrm{T}_{50}$ value was associated with using alcohol. Furthermore, the tertile with the lowest $T_{50}$ values had the highest Hb1Ac $(\mathrm{p}<0.001)$ and more often a history of retinopathy $(\mathrm{p}=0.016)$.

Determinants for serum calcification propensity were identified using linear regression (table 2). Gender was found to be the strongest determinant of $\mathrm{T}_{50}$, with females having a mean $\mathrm{T}_{50}$ of $249 \pm 65 \mathrm{~min}$, compared with $271 \pm 64 \mathrm{~min}$ for males (figure $2 \mathrm{~A}$, standardized beta -0.171 , adjusted $\left.\mathrm{R}^{2} 0.028, \mathrm{p}<0.001\right)$. Smoking was found to lower $\mathrm{T}_{50}$ (figure $2 \mathrm{C}$ ), as did a longer disease duration for diabetes. Interestingly, HbAlc was negatively associated with $\mathrm{T}_{50}$ as well (figure 2E, standardized (st) beta -0.141 , adjusted $\mathrm{R}^{2} 0.019, \mathrm{p}<0.001$ ), whereas low-density lipoprotein (LDL) cholesterol exhibited a significant, positive association (figure $2 \mathrm{~F}$ ). The use of insulin therapy was associated with a lower $T_{50}(247 \pm 69 \mathrm{~min}$ for insulin users vs $263 \pm 64 \mathrm{~min}$ for non-insulin dependent patients; st. beta -0.083 , adjusted $\mathrm{R}^{2} 0.006, \mathrm{p}=0.011$; figure $2 \mathrm{~B}$ ). We could not detect an association between the $\mathrm{T}_{50}$ and either documented macrovascular or microvascular disease as composite variables. Assessing all conditions separately, only the presence of diabetic retinopathy was found to be significantly associated with $T_{50}$.

Backward regression was used with all variables to investigate which variables would be significantly associated with $\mathrm{T}_{50}$ after correction for covariates. The final model is detailed in table 2. Sex, smoking status, systolic blood pressure, HbA1c, LDL cholesterol, total cholesterol, cholesterol/high-density lipoprotein ratio, and triglycerides all remained significant with the final model explaining $9.4 \%$ of the variance in $\mathrm{T}_{50}(\mathrm{p}<0.001)$.

\section{CONCLUSIONS}

In the present, study we explored the association between calcification propensity (measured using the $\mathrm{T}_{50}$ test) and indices of T2DM management, in particular HbA1c, in a large population of outpatients. Interestingly, we found that several factors reflecting an unfavorably disease status, namely a higher HbAlc, insulin dependence, and a longer history of diabetes, were all associated with lower $\mathrm{T}_{50}$ values. In multivariable analysis, only HbAlc remained significantly associated with $T_{50}$.

This may indicate that long-term glycemic control is a more important determinant for $\mathrm{T}_{50}$ than the use of insulin and disease duration. Furthermore, HbAlc remained significantly associated with $\mathrm{T}_{50}$ after adjusting for gender, smoking, LDL cholesterol, and systolic blood pressure, identifying HbAlc as an independent determinant. Importantly, poor glycemic control is thought to contribute to the development of vascular calcification, ${ }^{3}$ which is a strong predictor of cardiovascular complications and mortality. ${ }^{2}$ Therefore, the finding that functional serum calcification buffer capacity correlates to markers for glycemic control could be an important step in linking the pathophysiology of diabetes to the pathophysiology of vascular calcification. Given this relationship between better glycemic control and a lower $T_{50}$ value, the $T_{50}$ could prove to be relevant in the follow-up and cardiovascular risk management of patients with T2DM. It is an open question whether, for instance, glycation of factors involved in vascular calcification leads directly to an increased calcification propensity or whether other mechanisms are involved.

Female sex and lower LDL cholesterol levels were associated with lower $T_{50}$ values, indicative of an increased serum calcification propensity. Similarly, the risks of higher LDL cholesterol levels and low calcification propensity may add up to ultimately precipitate a macrovascular event. Serum $\mathrm{T}_{50}$ has previously been investigated in renal disease cohorts, including predialysis CKD 
patients, ${ }^{19} 24$ hemodialysis patients, ${ }^{25}{ }^{26}$ and renal transplantation patients. ${ }^{20}{ }^{21}$ Smith $e t a l^{19}$ found that women had a lower $\mathrm{T}_{50}$ in CKD stages 3 and 4 like in our study, whereas Pasch $e t a l^{25}$ found that women actually had a higher $\mathrm{T}_{50}$ than men (with a difference of about $10 \mathrm{~min}$ ), in a hemodialysis population. It is possible that the differences between these studies can be explained by the outsize cardiovascular risk, possibly partially CPP mediated, that is conferred by end-stage renal disease, which outweighs the effects of traditional cardiovascular risk factors, which may be more relevant in our non-CKD population and in a prehemodialysis population. On the other hand, Keyzer et $a l^{20}$ also did not detect an association between $\mathrm{T}_{50}$ and gender in a renal transplantation cohort, most of whom had undergone dialysis for over 5 years but who had higher $\mathrm{T}_{50}$ values after transplantation than our cohort of patients with diabetes. More studies will be required to elucidate whether associations between gender and calcification propensity, and between serum lipid levels and calcification propensity are disease specific.

Table 2 Univariable and multivariable linear regression analysis for determinants of serum $\mathrm{T}_{50}$

\begin{tabular}{|c|c|c|c|c|c|c|}
\hline & Univaria & analys & & Multivari & le analysis & \\
\hline & Beta & $\mathbf{R}^{2}$ & $P$ value & Beta & Partial $\mathbf{R}^{2}$ & $P$ value \\
\hline Age (years) & 0.024 & 0.000 & 0.911 & & & \\
\hline Sex & 22.435 & 0.029 & $<0.001$ & 27.097 & 0.026 & $<0.001$ \\
\hline Smoking & -22.579 & 0.017 & $<0.001$ & -18.998 & 0.015 & 0.003 \\
\hline Alcohol use & 8.140 & 0.003 & 0.108 & & & \\
\hline $\mathrm{BMI}\left(\mathrm{kg} / \mathrm{m}^{2}\right)$ & -0.492 & 0.002 & 0.240 & & & \\
\hline $\mathrm{SBP}(\mathrm{mm} \mathrm{Hg})$ & -0.253 & 0.004 & 0.068 & -0.354 & 0.004 & 0.025 \\
\hline $\mathrm{DBP}(\mathrm{mm} \mathrm{Hg})$ & -0.382 & 0.003 & 0.123 & & & \\
\hline Duration of diabetes (months) & -1.061 & 0.007 & 0.011 & & & \\
\hline $\mathrm{HbA} 1 \mathrm{c}(\mathrm{mmol} / \mathrm{mol})$ & -1.073 & 0.020 & $<0.001$ & -1.115 & 0.015 & $<0.001$ \\
\hline Total cholesterol (mmol/L) & 1.390 & 0.000 & 0.530 & -28.616 & 0.013 & $<0.001$ \\
\hline HDL cholesterol (mmol/L) & -7.930 & 0.002 & 0.188 & & & \\
\hline Total cholesterol/HDL ratio & 2.300 & 0.001 & 0.248 & -9.531 & 0.006 & 0.030 \\
\hline LDL cholesterol (mmol/L) & 6.323 & 0.006 & 0.015 & 43.982 & 0.020 & $<0.001$ \\
\hline Triglycerides (mmol/L) & -1.026 & 0.000 & 0.644 & 12.888 & 0.007 & 0.009 \\
\hline History of macrovascular event & -3.165 & 0.000 & 0.521 & & & \\
\hline History of AP & 9.491 & 0.001 & 0.245 & & & \\
\hline History of Ml & -0.971 & 0.000 & 0.899 & & & \\
\hline History of $\mathrm{PCl}$ & -19.443 & 0.002 & 0.150 & & & \\
\hline History of CABG & -11.923 & 0.002 & 0.227 & & & \\
\hline History of TIA & 14.635 & 0.002 & 0.220 & & & \\
\hline History of stroke & -4.294 & 0.000 & 0.631 & & & \\
\hline Microvascular complication & -2.448 & 0.000 & 0.604 & & & \\
\hline Retinopathy & -23.677 & 0.006 & 0.029 & -0.075 & 0.004 & 0.036 \\
\hline Peripheral neuropathy & -0.557 & 0.000 & 0.920 & & & \\
\hline Albuminuria & 0.541 & 0.000 & 0.931 & & & \\
\hline eGFR (mL/min/1.73 m²) & -0.036 & 0.001 & 0.416 & & & \\
\hline Albumin/creatinin ratio & -0.703 & 0.005 & 0.037 & & & \\
\hline Diet, \% (N) & 6.044 & 0.001 & 0.264 & & & \\
\hline Oral blood glucose lowering drugs, \% (N) & -1.057 & 0.000 & 0.838 & & & \\
\hline Insulin therapy, \% (N) & -16.035 & 0.007 & 0.012 & & & \\
\hline Cholesterol-lowering drugs, \% (N) & 4.477 & 0.001 & 0.399 & & & \\
\hline Antihypertensive therapy, \% (N) & -4.160 & 0.001 & 0.485 & & & \\
\hline
\end{tabular}

AP, angina pectoris; BMI, body mass index; CABG, coronary artery bypass grafting; DBP, diastolic blood pressure; eGFR, estimated glomerular filtration rate; $\mathrm{HbA} 1 \mathrm{c}$, hemoglobin $\mathrm{A} 1 \mathrm{c} ; \mathrm{HDL}$, high-density lipoprotein; LDL, low-density lipoprotein; MI, myocardial infarction; PCI, percutaneous coronary intervention; SBP, systolic blood pressure; TIA, transient ischemic attack. 

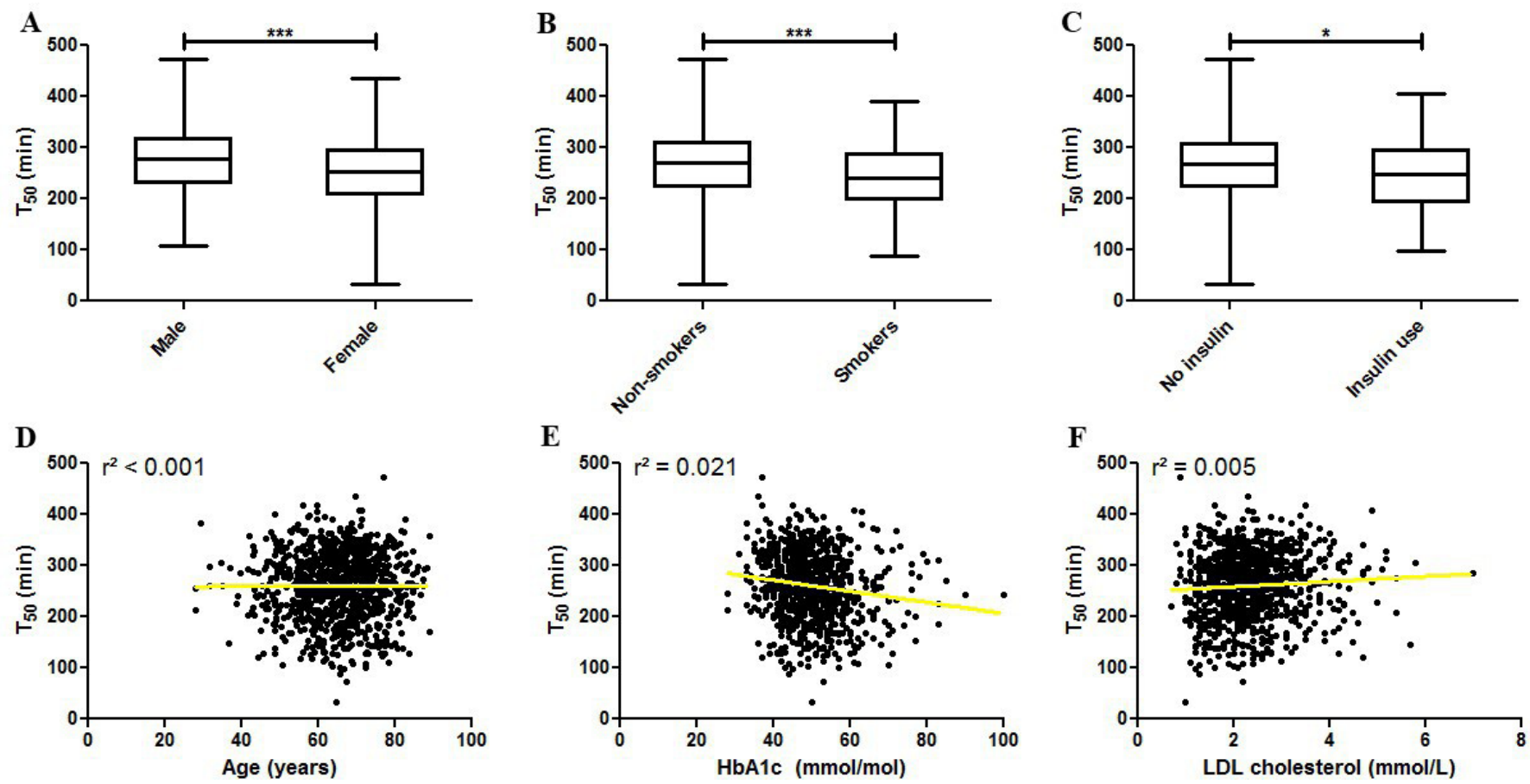

Figure 2 Associations between baseline patient characteristics and serum $T_{50^{*}}$ (A) $T_{50}$ is significantly lower in female patients with diabetes. Similarly, $T_{50}$ is decreased in (B) smokers and in (C) patients using insulin. (D) There is no association between age and $T_{50}$. $(E)$ The association between $T_{50}$ and $H b A 1 c$ is negative and $(F)$ the association between $T_{50}$ and LDL cholesterol is positive. ${ }^{*} \mathrm{P}<0.05,{ }^{* \star} \mathrm{p}<0.001$. HbA1c, hemoglobin $\mathrm{A} 1 \mathrm{c}$; LDL, low-density lipoprotein.

Interestingly, serum calcification propensity was not associated with estimated glomerular filtration rate in the present T2DM population but was associated with the albumin/creatinine ratio. This indicates a window between the occurrence of incipient renal damage and the impairment of renal function in which serum $\mathrm{T}_{50}$ will start to decrease. Given the pathophysiology of CPPs as a mechanism to buffer calcium and phosphate overload and the relevance of the kidney in regulating phosphate excretion through fibroblast growth factor 23 and Klotho, it is possible that the early disturbances in these factors that occur already during subtle renal injury can rapidly result in an increased serum calcification propensity.

We did not detect an association between serum $T_{50}$ and a history of macrovascular disease or the presence of microvascular disease. The only exception was the presence of diabetic retinopathy, but it had such a low prevalence in our cohort that independent validation in larger or more tailored cohorts will be required to provide reliable answers. It should be noted that macrovascular disease was not assessed prospectively and that a $\mathrm{T}_{50}$ measurement at baseline may be a better predictor for future events, rather than reflect past events.

In summary, in this cohort of patients with T2DM, we found that serum calcification propensity was negatively and independently associated with $\mathrm{HbA1c}$, which suggests that better glycemic control may correlate with a less pronounced development of vascular calcification, which ultimately might lead to better cardiovascular outcomes. We were, however, unable to establish an association with the past occurrence of macrovascular disease or with the presence of microvascular disease (with the exception of retinopathy in our univariable linear regression analysis). Prospective studies will be required to elucidate the role of serum calcification propensity and the $\mathrm{T}_{50}$ measurement in the vascular burden in diabetes and cardiovascular outcomes.

Acknowledgements The authors want to thank the Zwols Wetenschapsfonds Isala Klinieken (ZWIK) and the Isala Innovatie and Wetenschapsfonds for their financial support.

Contributors RM: measurements, statistical analysis, interpretation of data, and writing manuscript. AvdV: statistical analysis and writing manuscript. AP: design, measurements, and critically reviewing manuscript. GH: measurements and critically reviewing manuscript. FW: design, measurements, interpretation of data, writing manuscript and collecting funds. HJGB and HvG: design, interpretation of data, writing manuscript, and collecting funds. J-LH: design, interpretation of data, and critically reviewing manuscript. PRvD: design, measurements, statistical analysis, interpretation of data, writing manuscript, and collecting funds.

Funding This work has been funded by the ZWIK and the Isala Innovatie and Wetenschapsfonds (grant number INN01717).

Disclaimer Both funders had no influence in the design of the study and collection, analysis, and interpretation of data and in writing the manuscript.

Competing interests All authors have approved the final version of the manuscript. AP is an employee and stockholder of Calciscon.

Patient consent for publication Not required.

Ethics approval The study protocol was registered prior to the start of the study (study ID METC 11.10117) and approved by the Medical Ethical Committee of Isala (Zwolle, the Netherlands).

Provenance and peer review Not commissioned; externally peer reviewed.

Data availability statement Data are available on reasonable request.

Open access This is an open access article distributed in accordance with the Creative Commons Attribution 4.0 Unported (CC BY 4.0) license, which permits others to copy, redistribute, remix, transform and build upon this work for any 
purpose, provided the original work is properly cited, a link to the licence is given, and indication of whether changes were made. See: https://creativecommons.org/ licenses/by/4.0/.

ORCID iD

Peter R van Dijk http://orcid.org/0000-0002-9702-6551

\section{REFERENCES}

1 Low Wang CC, Hess CN, Hiatt WR, et al. Clinical Update: Cardiovascular Disease in Diabetes Mellitus: Atherosclerotic Cardiovascular Disease and Heart Failure in Type 2 Diabetes Mellitus - Mechanisms, Management, and Clinical Considerations. Circulation 2016;133:2459-502.

2 Beckman JA, Creager MA, Libby P. Diabetes and atherosclerosis: epidemiology, pathophysiology, and management. JAMA 2002;287:2570-81.

3 van Haelst STW, Haitjema S, de Vries J-PPM, et al. Patients with diabetes differ in atherosclerotic plaque characteristics and have worse clinical outcome after iliofemoral endarterectomy compared with patients without diabetes. J Vasc Surg 2017;65:414-21.

4 Dhore CR, Cleutjens JP, Lutgens E, et al. Differential expression of bone matrix regulatory proteins in human atherosclerotic plaques. Arterioscler Thromb Vasc Biol 2001;21:1998-2003.

5 Shanahan CM, Cary NR, Metcalfe JC, et al. High expression of genes for calcification-regulating proteins in human atherosclerotic plaques. J Clin Invest 1994;93:2393-402.

6 Pasch A, Farese S, Gräber S, et al. Nanoparticle-Based test measures overall propensity for calcification in serum. J Am Soc Nephrol 2012;23:1744-52.

7 Aghagolzadeh P, Bachtler M, Bijarnia R, et al. Calcification of vascular smooth muscle cells is induced by secondary calciprotein particles and enhanced by tumor necrosis factor- $\alpha$. Atherosclerosis 2016;251:404-14.

8 Hamano T, Matsui I, Mikami S, et al. Fetuin-Mineral complex reflects extraosseous calcification stress in CKD. J Am Soc Nephrol 2010;21:1998-2007.

9 Matsui I, Hamano T, Mikami S, et al. Fully phosphorylated fetuin-A forms a mineral complex in the serum of rats with adenine-induced renal failure. Kidney Int 2009;75:915-28.

10 Heiss A, DuChesne A, Denecke B, et al. Structural basis of calcification inhibition by alpha 2-HS glycoprotein/fetuin-A Formation of colloidal calciprotein particles. J Biol Chem 2003;278:13333-41.

11 Heiss A, Eckert T, Aretz A, et al. Hierarchical role of fetuin-A and acidic serum proteins in the formation and stabilization of calcium phosphate particles. J Biol Chem 2008;283:14815-25.

12 Heiss A, Jahnen-Dechent W, Endo H, et al. Structural dynamics of a colloidal protein-mineral complex bestowing on calcium phosphate a high solubility in biological fluids. Biointerphases 2007;2:16-20.
13 Heiss A, Pipich V, Jahnen-Dechent W, et al. Fetuin-A is a mineral carrier protein: small angle neutron scattering provides new insight on fetuin-A controlled calcification inhibition. Biophys $J$ 2010;99:3986-95.

14 Shanahan CM, Cary NR, Salisbury JR, et al. Medial localization of mineralization-regulating proteins in association with Mönckeberg's sclerosis: evidence for smooth muscle cell-mediated vascular calcification. Circulation 1999;100:2168-76.

15 Giachelli CM, Bae N, Almeida M, et al. Osteopontin is elevated during neointima formation in rat arteries and is a novel component of human atherosclerotic plaques. J Clin Invest 1993;92:1686-96.

16 Ikeda T, Shirasawa T, Esaki Y, et al. Osteopontin mRNA is expressed by smooth muscle-derived foam cells in human atherosclerotic lesions of the aorta. J Clin Invest 1993;92:2814-20.

17 Steitz SA, Speer MY, Curinga G, et al. Giachelli cm: smooth muscle cell phenotypic transition associated with calcification: upregulation of Cbfa1 and downregulation of smooth muscle lineage markers. Circ Res 2001;89:1147-54.

18 Pasch A, Jahnen-Dechent W, Smith ER. Phosphate, calcification in blood, and mineral stress: the physiologic blood mineral buffering system and its association with cardiovascular risk. Int J Nephrol 2018;2018:1-5.

19 Smith ER, Ford ML, Tomlinson LA, et al. Serum calcification propensity predicts all-cause mortality in predialysis CKD. J Am Soc Nephrol 2014;25:339-48.

20 Keyzer CA, de Borst MH, van den Berg E, et al. Calcification propensity and survival among renal transplant recipients. J Am Soc Nephrol 2016;27:239-48.

21 Dahle DO, Åsberg A, Hartmann A, et al. Serum calcification propensity is a strong and independent determinant of cardiac and all-cause mortality in kidney transplant recipients. Am J Transplant 2016;16:204-12.

22 Roelofsen Y, Hendriks SH, Sieverink F, et al. Design of the e-Vita diabetes mellitus study: effects and use of an interactive online care platform in patients with type 2 diabetes (e-VitaDM-1/ZODIAC-40). BMC Endocr Disord 2014;14:22-6823.

23 Hendriks SH, van Soldt EGW, van Vugt M, et al. Lifestyle and emotional well-being in men and women with type 2 diabetes (eVitaDM-4; ZODIAC-48). Eur J Gen Pract 2017;23:83-90.

24 Pruijm M, Lu Y, Megdiche F, et al. Serum calcification propensity is associated with renal tissue oxygenation and resistive index in patients with arterial hypertension or chronic kidney disease. $J$ Hypertens 2017;35:2044-52.

25 Pasch A, Block GA, Bachtler M, et al. Blood calcification propensity, cardiovascular events, and survival in patients receiving hemodialysis in the evolve trial. Clin J Am Soc Nephrol 2017;12:315-22.

26 Dekker M, Pasch A, van der Sande F, et al. High-Flux hemodialysis and high-volume hemodiafiltration improve serum calcification propensity. PLoS One 2016;11:e0151508. 